ments. A. C. Seward is (dis)credited with stifling research in the field for almost 40 years through his 1931 critique of the known or asserted Precambrian fossil record. If Seward's call for "more critical examination of the evidence" indeed had such an effect, surely the blame lies with those who might have taken up the challenge but didn't.

Nor does Schopf spare himself; the account of how, in 1965, he helped his professor take advantage of a peer-review commission to get the edge on a competitor would raise more than eyebrows if the act were committed today. The 1983 paper by Awramik, Schopf and Walter, reporting the world's oldest fossils from the Warrawoona Group in western Australia, is called a fiasco, because the original sampling spot could not be found; Schopf's own 1993 paper is credited with the real discovery. However, the earlier work showed that these fossils existed, and so was no more a fiasco than Christopher Columbus's voyage (about which there was also uncertainty over exact locations). In this vein, Schopf's paper rather compares to Amerigo Vespucci's voyages. Isn't that good enough?

The book is not free from bloopers, which could have been avoided by more careful reviewing. The map of North America on page 37 should be deeply offensive to those of a Canadian persuasion in New Brunswick and Nova Scotia; the Bolsheviks are credited with seizing power from the czar (who had actually abdicated more than half a year before the Bolshevik coup); and atmospheric carbon dioxide is said to act "like the windows of a greenhouse, it holds in heat, storing it in the chemical bonds that knit its atoms together" (no, it absorbs infrared radiation and converts it to heat in the atmosphere; greenhouse windows mostly just keep warm air in).

A central message of the book is that Precambrian biology differs fundamentally from Phanerozoic biology. This is indeed so; the transition between the two stands out as the greatest revolution in the history of the biosphere. Schopf makes a claim for 'hypobradytely' - extremely slow evolution during the Precambrian, owing to the predominance of asexual reproduction, "a new fundamental insight that ... stands out as one of the most striking findings ... since Darwin". Whether or not this bold claim will stand the test of time, the measurement of evolutionary rates in fossil microorganisms faces formidable difficulties, because in general only morphology is preserved, and poorly so.

Another obstacle to understanding early fossils is the bias imposed by the small subset of life-forms that have happened to survive until today. By using living organisms as our models (for example, by identifying the earliest fossils as cyanobacteria, as Schopf does), we may blind ourselves to the host of extinct organisms, and unwittingly introduce hypo- bradytely as a taxonomic artefact.

This problem follows us into astrobiology; we need methods to recognize life-forms, fossil or living, that may be totally unrelated to those on Earth. In an epilogue on that theme, Schopf mischievously places a chapter on two of the most famous howlers in palaeontology — Scheuchzer's 'Homo diluvii testis' and Beringer's 'Lügensteine' side-by-side with a critical discussion and effective debunking of the claim for ancient life in the Martian meteorite ALH84001 (Schopf was the invited sceptic at the NASA press conference in 1996). In no way does he deride the field, however. Like Seward 65 years earlier, Schopf has advocated constructive scepticism in a field of research where even the existence of the subject is in doubt. Like Seward, he deserves praise for this.

Stefan Bengtson is in the Department of Palaeozoology, Swedish Museum of Natural History, Box 50007, SE-104 05 Stockholm, Sweden.

\section{Damsels and dragons}

\section{Dragonflies: Behaviour and Ecology of Odonata}

by Philip S. Corbet

Harley: 1999.882 pp. $£ 62.50$

\section{Mike Siva-Jothy}

Dragonflies have almost certainly been using the same habitats in the same way for more than 250 million years. But, despite the general conservatism in this insect order, there is considerable variation in many aspects of their larval and adult behaviour, much of which is influenced by ecology. Philip Corbet's book is a rare beast: a truly authoritative natural history monograph dealing with a large taxon, and not strictly the behavioural ecology text that the title suggests.

Almost 20 years ago, as a student, I heard a rumour that Corbet, the patriarch of odonatologists, was about to write a new book. As the years passed, expectations grew, but later turned into concern that perhaps the work would not be finished. Key contributors to the material and impetus for the book passed away while it was in utero, including the extraordinary Peter Miller, whose research contributes something to every chapter. Not surprisingly, when the book eventually appeared, there was concern that it would not live up to 18 years of anticipation. But it did. Every aspect of biology touched upon is explained clearly and carefully by an author who has truly made the effort to understand it all.

Corbet has synthesized a phenomenal amount of material. He deliberately does not organize the book around the currently important questions in evolutionary ecology. Instead he has written a cleverly cross-referenced and indexed text that provides all the

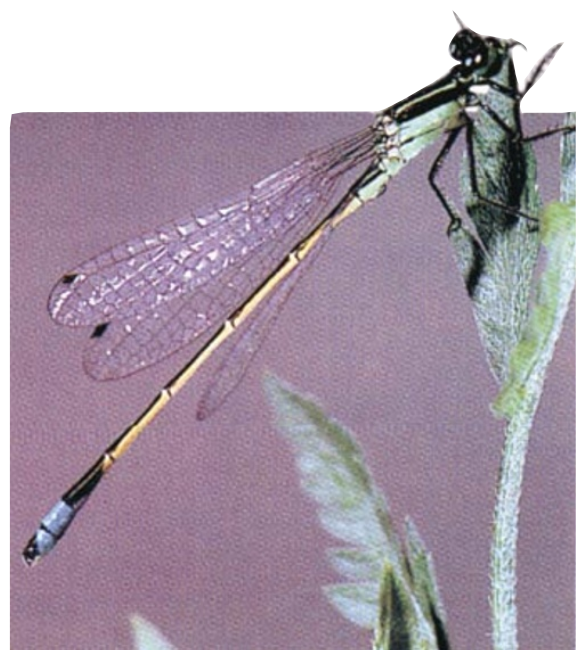

raw material from which ideas can be developed, or key information sought. The value in this approach is that, as current questions are replaced, the book will still provide wellorganized information.

The book follows the sequence of the key life-history stages, starting with eggs, moving through larval behaviour and life-history traits, then dealing with emergence, preadult development and, in the largest chapter, reproduction. This is the most complete synthesis of behavioural, ecological and background material from a single taxonomic group I have ever seen. As though it were not enough to synthesize so much information, Corbet has also provided a large set of appendices giving valuable follow-up material from each chapter.

Corbet never pulls his linguistic punches, and uses strictly correct entomological terms throughout. This is initially daunting (as is the uncompromising use of binomial nomenclature), but the reasoning behind it is important: these terms are increasingly falling into disuse as well as misuse. The glossary at the end is invaluable.

I have only two quibbles. First, most of the figures are directly reproduced from their original sources, which means sometimes there is a hotchpotch of illustrative styles that does not always do justice to the text. Second, an illustrated key of the major taxa would have been a useful foil to the abundance of binomial names. But these criticisms are pebbles, thrown at an edifice that will sit next to Bert Hölldobler and Edward O. Wilson's The Ants (Springer, 1990) as one of the definitive natural history texts of the twentieth century. Mike Siva-Jothy is in the Department of Animal and Plant Sciences, University of Sheffield, Sheffield S10 2TN, UK.

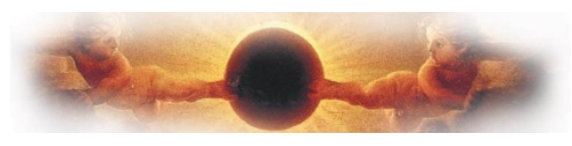

correction In the review "A user's guide to two minutes of totality" by Jay M. Pasachoff (Nature 399, 651-652; 1999), the photograph of the total eclipse of the Sun was taken by the Extreme-ultraviolet Imaging Telescope Team, Solar and Heliospheric Observatory, NASA and ESA. 


\section{A user's guide to two minutes of totality}

\author{
Total Eclipses: Science, \\ Observations, Myths and Legends \\ by Pierre Guillermier and Serge Koutchmy

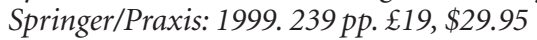 \\ Solar Eclipse \\ by Thomas Crump \\ Constable: 1999. 256 pp. $£ 9.99$ (pbk)
}

\section{Eclipse! The What, Where, When, Why \& How Guide to Watching Solar and Lunar Eclipses}

by Philip S. Harrington

Wiley: 1997. 280 pp. $£ 11.99$, $\$ 16.95$

\section{The Sun in Eclipse (Practical}

\section{Astronomy)}

by Michael Maunder and Patrick Moore Springer: 1997.217 pp. \$29.95, £20

\section{UK Solar Eclipses from Year 1}

by Sheridan Williams

Clock Tower Press: 1996.100 pp. 111.95

\section{Jay M.Pasachoff}

The total eclipse of 11 August that will follow a path from the Atlantic through Europe and over to India will be, for those fortunate enough to see it, one of the most wonderful experiences of their lives. For two minutes and some seconds in Europe, the blue sky will disappear, revealing the glories of the solar corona that it normally hides.

The importance of these two minutes, and the fact that one can, and should, look at the corona during this time without any filters, is unfortunately often hidden by the marketing blitz for eye-protection filters. These filters are fine in their place, but they are only for taking occasional glances at the partial phases. Indeed, putting them into eyeglass form, instead of rectangular sheets, may encourage people to use them for too long. Further, since the partial phases are not fundamentally interesting to look at, one can do almost as well by looking at the pinhole images of the crescent Sun that will be projected beneath trees and bushes.

There are several good books to choose from for background information on solar eclipses. Total Eclipses, a collaboration between an amateur astronomer, Pierre Guillermier, and one of the most active and enthusiastic professional eclipse scientists, Serge Koutchmy, gives a variety of information on observing eclipses for the novice and on the value of eclipses to professionals. The book, which is well illustrated, gives an authoritative survey of solar astronomy and puts solar eclipses in their scientific place.

It covers the solar survey; how to observe the Sun both inside and outside eclipses; the celestial motions that cause eclipses; historical and mythological eclipse stories; a description of what it is like to be at an

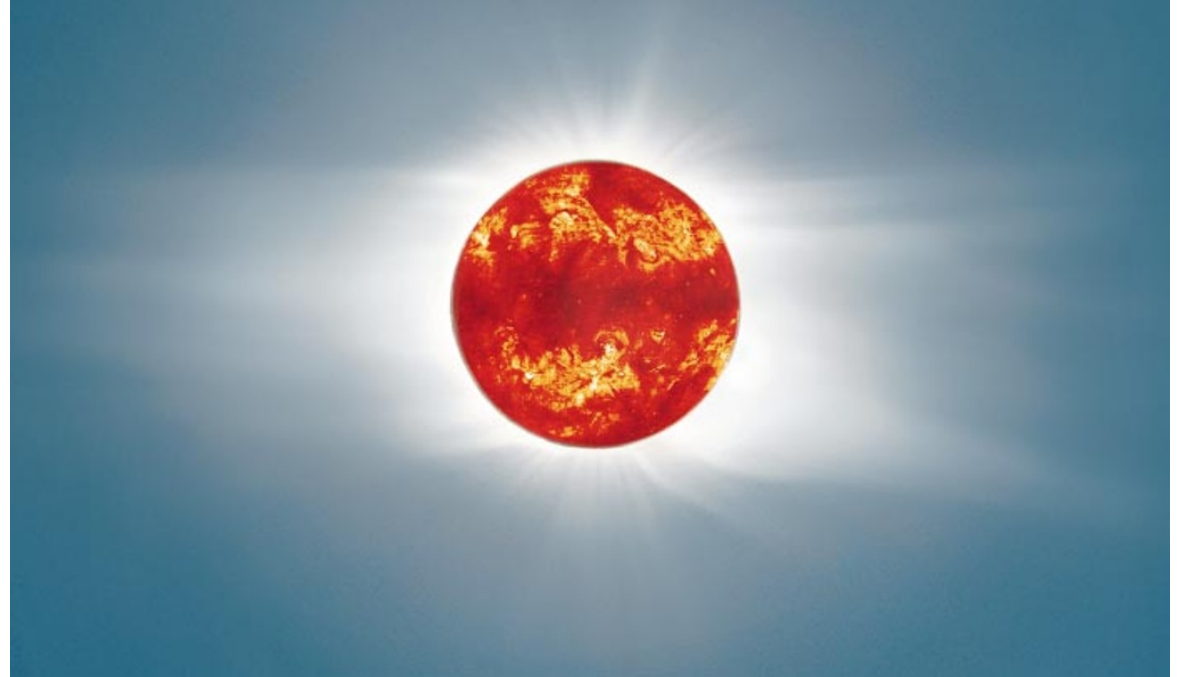

Do look now: only during totality is it safe to look at the solar corona with unprotected eyes.

eclipse; and reliable information on how to photograph solar and lunar eclipses. One of the appendices, obviously written by Koutchmy, discusses eclipse research. Another gives detailed information on this summer's eclipse. In spite of the perhaps inevitably disjointed collaboration between an amateur and a professional (a fault shared by my own co-authored Cambridge Eclipse Photography Guide, with Michael A. Covington; Cambridge University Press), readers can find information at an interesting and appropriate level and can be sure that their guides are knowledgeable.

Guillermier and Koutchmy discuss not merely famous eclipses in history and literature, but even try to track down an eclipse described in a Tintin story. Observers will benefit from a phase-by-phase set of recommendations on how to observe and photograph the eclipse. A variety of space observations, which are now capable of observing many aspects of the solar corona, are also discussed, including those of the current Solar and Heliospheric Observatory (SOHO). Unfortunately, the book (as of the proof stage) has not been updated since the original French edition, and so the remarkable high-resolution coronal images taken by the Transition Region and Coronal Explorer (TRACE) do not appear.

Thomas Crump, in Solar Eclipse, sets out to describe this eclipse, and eclipses in general, from an anthropological stance. He gleans his information from a variety of sources, necessary because he has never seen an eclipse himself. So, although many of the stories are interesting, flaws creep in, such as a comment confusing the formula for the Balmer series, which applies only to hydrogen and a few other one-electron ions, with the wavelengths of all the Fraunhofer lines.
More serious are the gaps in the single page of warning, at the beginning of the book, about viewing and photographing the eclipse. For observing information, it is better to rely on experienced observers.

Nevertheless, the stories and explanations about eclipses make the book worth reading. I hadn't known the background of horseracing's Eclipse Stakes, which is named after the racehorse Eclipse, foaled on the date of a solar eclipse and owned by King George IV when he was Prince of Wales.

One chapter is devoted to three scientific investigations traditional of eclipses: the history of 'coronium', and how it became known to consist of gases like iron at temperatures of millions of degrees, is well told. The story of the tests of Einstein's general theory of relativity at the 1919 eclipse remains of interest, even though observations using other methods, most recently with the star positions measured by the European Space Agency's Hipparcos spacecraft, give the result more accurately and obviate the need for further eclipse observations of the deflection of light. And the link between historical eclipse observations and the rotation of the Earth, perhaps leading to improved geophysical understanding of such terrestrial processes as post-glacial uplift, closes the chapter.

Philip Harrington, an experienced observer, provides a straightforward guide to eclipse watching in Eclipse! With only a nod to history, he moves to a clear and simple description of how to observe and photograph eclipses, also describing the darkroom and computer techniques that can be used. The heart of the book is a set of descriptions and maps of the paths from which solar and lunar eclipses can be seen between 1998 and 2017, the latter being the date of the next total 
solar eclipse visible from the United States. The solar eclipse maps show only the paths of totality, and not the extent of partial phases, but are fascinating nevertheless and are all that is needed for those of us who will travel to view totality. Many of us are already plotting how to view the 23 November 2003 total eclipse that crosses land only over Antarctica.

In The Sun in Eclipse, Michael Maunder and Patrick Moore have written a very practical set of instructions for observing and photographing the eclipse, which fits well in Moore's "Practical Astronomy" series. The information obviously comes from knowledgeable and experienced observers. The discussion of filters and projection methods for solar observation, for example, goes on for 16 pages, and includes careful descriptions of the best filters, a discussion of pinhole projection and a list of "filters which must never be used". Detailed hints on focusing and on the problems of camera shake are wise.

A table lists future eclipses until 2020, but the only map for 11 August is that of totality over Cornwall and Alderney, even though it is so easy to travel from England to the Continent, where weather statistics are more favourable. It is hard to understand why so many people are devoted to seeing the eclipse in England instead of crossing the channel.

Moore has a distillation of his discussion in Patrick Moore's Guide to the 1999 Total Eclipse (Macmillan/Boxtree), whose proceeds go towards building a planetarium in West Sussex. Maps include small versions of the standard ones by Fred Espenak of NASA; they are handy to have, but are not well reproduced, being small and on inexpensive paper.

Sheridan Williams's idiosyncratic UK Solar Eclipses from Year 1 provides maps of all eclipses crossing England over three millennia, and shows how to observe them. Any eclipse buff should have one. Totality: Eclipses of the Sun (2nd edn) by Mark Littman, Fred Willcox and Fred Espenak (Oxford University Press) is late in the publication of eclipse books, but is by very experienced buffs.

The few professional teams of eclipse observers will be overwhelmed by the amateur astronomers and, even more, by the many tourists who will travel into the band of totality. Let us echo Edmond Halley's sentiment from his map predicting the path of the 1715 eclipse over England: "We wish our Astronomical Friends a Clear Sky."

Jay M. Pasachoff is in the Department of Astronomy, Williams College, 3 Lab Campus Drive, Williamstown, Massachusetts 01267, USA, and is Chair of the Working Group on Eclipses of the solar commissions of the International Astronomical Union.

\section{An awkward dinner guest}

\section{Mapping the Mind}

by Rita Carter

Weidenfeld \& Nicolson: 1998. 224 pp. $\mathfrak{E} 25, \$ 29.95$

\section{Jeffrey Gray}

In the early 1970s I had a very bright student, John Churcher, who started doing experimental psychology, then quit to study Chinese, only to come back a term later to psychology. His reason for returning was that the experience of psychology had made it impossible for him to take part in standard dinner-party conversation. His assumptions were just too different from those of everyone else. (In those days there were very few students of psychology or neuroscience.)

I knew just what John meant: it was not so much a question of having different information to bring to bear on the topic of the evening, much more to do with the conceptual framework within which it was approached. Thirty years on, despite the extensive marination of contemporary society in psychology and neuroscience, the 'Churcher gap' is still with us. So, will Rita Carter's beautifully produced and entertainingly written survey of the 'landscape of the brain' help us cross it?

Information there is aplenty, nugget after nugget of it to stimulate and tease the most jaded palate. Many of the nuggets come from recent imaging studies of the human brain in action (prettily illustrated with pictures of brains lighting up here and there in response to this and that). The attentive reader will learn to name particular regions of the brain (amygdala, hypothalamus, hippocampus...) and to attach neat labels to them (fear, sex, memory...). The more attentive reader might, however, wonder whether this kind of paired associate learning throws any real light on the way the brain actually works.

Other nuggets come from the strange vicissitudes that befall people who have had damage to discrete parts of the brain - the kind of case study that Oliver Sacks has made his own - or from various visual and other illusions taken from the treasure-house of psychophysics. Carter does an excellent job of putting together these different kinds of nugget into a unified, diverting and fastmoving narrative.

But, but... the more I read this book, the more concerned I became about the effect it will have on dinner-party conversation. It is, of course, the job of scientific journalism to make science easy to digest, but Carter makes it all too easy. Most of her story is presented as though it were established fact, but very little of it is; and rarely is the reader given any clues for distinguishing well-supported evidence from mere speculation. Above all, one is given the impression that wonderful new machines like PET scanners have opened up startling windows on the brain/mind - lo! We now just have to look in to see what is going on there.

There is hardly any discussion of the way in which behavioural neuroscience sifts evidence, of the conceptual frameworks it uses or the problems they present, or of the difficulties of integrating theory and evidence that come from different starting points. This last issue is fudged to the point of obscurity. There are, for example, long passages that purport to be about brain function, but which are, in fact, filched from common experience and reclothed in spurious neuroscientific talk that only the worker in the field will know has no empirical support.

The conceptual confusions that permeate the book become most worrying when we reach those most likely dinner-party topics: consciousness, free will and the responsibility for one's actions. Neural messages are repeatedly sent from the 'conscious brain' to the 'unconscious brain', or in the other direction, in a way that builds shamelessly upon Cartesian dualist intuitions which are then in the final chapter piously — but without good reason given - dismissed. (The 'conscious brain', by the way, is usually said to lie in the cerebral cortex, sometimes specifically in the frontal cortex; this hypothesis, even if made intelligible, is as yet unsupported by any serious evidence. Equally unsupported is its complement, that everything below the cortex makes up the 'unconscious brain.)

The book relentlessly blurs the critical divide between frank damage to the brain as the clear cause of behavioural derangement and variation in the activity of the brain as a correlate of behavioural variation (a correlation from which, of course, no direction of causality can be inferred). So, towards the end of the book, we are asked to take seriously the hypothesis that the massacres of Armenians by Turks, Jews by Nazis, Cambodians by Pol Pot and Tutsis by Hutus were all brought about by "spasms of overactivity in the orbito-frontal and medial prefrontal cortex".

This absurd extension of neuroscience into history and politics is what I dread most to find at the next dinner party. The Churcher gap, alas, is alive and well.

Jeffrey Gray is at the Institute of Psychiatry and ReNeuron Ltd, De Crespigny Park, Denmark Hill, London SE5 8AF, UK.

Mapping the Mind was short-listed for the 1999 Rhône-Poulenc Prize for Science Books see page 654 . 